\title{
Security concerns of people using wheelchair
}

\author{
Jitka ČIHOUNKOVA*, Alena SKOTÁKOVÁ, \& Jindřiška KOHOUTKOVÁ \\ Masaryk University, Faculty of sport studies, Department of gymnastics and combatives (Czech \\ Republic)
}

\author{
5th IMACSSS World Scientific Congress Abstracts, Rio Maior (Portugal), October 6-8 \\ Section: Adaptative MA\&CS \\ Type: Oral communication
}

\section{Introduction}

When considering conflict situations, it is generally known that people with disabilities are more vulnerable to violence than their non-disabled counterparts. Security concerns are particularly widespread among people with limited mobility or sight impairment. One notable consequence of this fear is higher risk of isolation, because the people themselves are afraid to go out without assistance (Kane, 2008). Because of this fact it is worthy for disabled people to be trained in selfdefence to support their self-confidence and courage (Wong, 1991).

This study was carried out as a starting point for designing a course of self-defence for people using wheelchair. Identifying the level of self-confidence in physically disabled people in the various types of conflict situations is the main aim of the study.

\section{Methodology}

39 people using wheelchair participate in the research (23 male, 16 female; mean age $\pm \mathrm{SD}=38.8 \pm$ 10.7 years; 26 participants used assistant regularly, 13 did not; 18 with completed primary education, 17 secondary education, 4 with a university degree; 13 using electrical wheelchair, 10 mechanical, 16 both).

We used a set of questions to determine the degree of self-confidence in self-defence situations such as prevention, verbal conflict and physical assault. This questionnaire was developed as a result of specific research at Masaryk University and used exploratory methods based on experience of disabled people with risky or violent behavior towards this specific group and their security concerns (Kohoutková, Čihounková, Skotáková, \& Reguli, 2015). The questionnaire was modified to assess experiences of people in wheelchair.

The data was collected personally, so the form of the questionnaire led to a form of a structured interview. The interview was divided into 3 sections evaluating the degree of self-confidence in self-defence situations, such as verbal conflict, physical assault (such as "If I were physically attacked I would know what to do", "It is easy for me to respond to physical conflict", "I feel confident solving physical conflict") and prevention. Each question was assessed by a 5 - point ranking Likert scale to determine the level of agreement. (1 - I totally disagree, 5 - I totally agree).

We searched for differences in gender (male vs. female), education (primary school, secondary school, university). Answers were quantified in excel and then converted into Statistica software for statistical processing. The Mann-Whitney $U$ test was used to assess the differences between two groups (gender, education, assistant). Kruskal-Wallis ANOVA was used to assess the differences between three groups (education, type of wheelchair). The level of significance was set at $p<0.05$. 


\section{Results}

Overall, people in wheelchair are not sure about the level of their confidence when they are asked about their crime prevention. They are even less confident when it comes to solving and responding to physical conflict. They feel more confident in a situation which they can affect by not provoking the conflict or be more alert in a potentially dangerous situation. People in wheelchair with primary school education feel more confident in solving verbal conflict than those with higher education ( $p=0.025747)$.

The second section of the questionnaire offers several different situations they can be scared of. The situations include physical conflict. Overall, people in wheelchair are scared of physical attack, grabbing and pulling out the personal belongings and inappropriate proposals at night. People in wheelchair with personal assistant are more scared of the situation than those with no assistant ( $p$ $=0.017155$ ).

Last part consists of 3 statements and focuses on strategies of people in wheelchair. Overall, people in wheelchair avoid situations they are scared of the most, they try not to limit themselves and face their fears. Men totally agree with the statement "I try to face my fear and not to limit myself in life" while women are not that confident in this statement $(p=0.013351)$.

\section{Discussion and conclusion}

Despite the significant difference found in self-confidence between men and women, men do not necessarily fear less than women. They just do not show their fear openly (Vaccaro, Schrock, \& McCabe, 2011). It was also found that people in wheelchair using assistant are more afraid of physical conflict than those with no assistant. The reason could be that people in wheelchair using an assistant have a higher degree of disability or that they rely on their assistants and feel more vulnerable without their help. Unfortunately, we did not do any research into this issue. This area would be worth exploring.

People with disabilities feel more vulnerable when being a crime victim (Kane, 2008; Wong, 1991), therefore it is definitely worthy for disabled people to be trained in self-defence techniques. Apart from the physical benefit it gives them sense of "calm and confidence" and "a fighting chance" in situations that can be dangerous, sometimes life-threatening.

\section{References}

Kane, J. (2008). Violence and disability. Luxembourg: EUR-OP. Retrieved from http://www.kaneinternational.com.au/assets/daphne6 violence-and-disabiity english 1.pdf

Kohoutková, J., Čihounková, J., Skotáková, A., \& Reguli, Z. (2015). Self-defence for people with visual impairments. Ido Movement for Culture. Journal of Martial Arts Anthropology, 15(2), 33-36.

Vaccaro, C. A., Schrock, D. P., \& McCabe, J. M. (2011). Managing Emotional Manhood: Fighting and Fostering Fear in Mixed Martial Arts. Social Psychology Quarterly, 74(4), 414-437.

Wong, H. (1991, August 30). More Power to the Disabled: Self-Defense Project Gives Handicapped a Fighting Chance. Los Angeles Times. Retrieved from http://articles.latimes.com/1991-0830/news/vw-1444 1 fighting-chance

Key words: Self-defence; physical disability; crime prevention; martial arts; combat sports.

This study is supported by the project of "Vliv kurzu Sebeobrany na některé psychické charakteristiky osob s tělesným postižením na vozíku” (MUNI/A/1300/2015). 